\title{
Sealing of PEO Coated AZ91 Magnesium Alloy Using La-Based Solutions
}

\author{
Luca Pezzato, ${ }^{1}$ Katya Brunelli, ${ }^{1}$ Riccardo Babbolin, ${ }^{1}$ Paolo Dolcet, ${ }^{2}$ and Manuele Dabalà ${ }^{1}$ \\ ${ }^{1}$ Department of Industrial Engineering, University of Padua, Via Marzolo 9, 35131 Padua, Italy \\ ${ }^{2}$ Department of Chemical Science, University of Padua, INSTM, UdR Padua and ICMATE-CNR, Padua, Italy
}

Correspondence should be addressed to Luca Pezzato; lucapezzato@virgilio.it

Received 31 August 2016; Revised 28 November 2016; Accepted 10 January 2017; Published 30 January 2017

Academic Editor: Flavio Deflorian

Copyright (C) 2017 Luca Pezzato et al. This is an open access article distributed under the Creative Commons Attribution License, which permits unrestricted use, distribution, and reproduction in any medium, provided the original work is properly cited.

In this work, solutions containing lanthanum salts were used for a post-treatment of sealing to increase the corrosion resistance of PEO coated AZ91 alloy. PEO coatings were produced on samples of AZ91 magnesium alloy using an alkaline solution containing sodium hydroxide, sodium phosphates, and sodium silicates. The sealing treatment was performed in a solution containing $12 \mathrm{~g} / \mathrm{L}$ of $\mathrm{La}\left(\mathrm{NO}_{3}\right)_{3}$ at $\mathrm{pH} 4$ at different temperatures and for different treatment times. Potentiodynamic polarization test, an EIS test, showed that the sealing treatment with solution containing lanthanum nitrate caused a remarkable increase in the corrosion resistance. The corrosion behavior was correlated with the surface morphology and elemental composition evaluated with scanning electron microscope (SEM), X-ray diffraction (XRD), and X-ray photoelectron spectroscopy (XPS). In particular, the sealing treatment at $50^{\circ} \mathrm{C}$ for $30 \mathrm{~min}$ resulted in being the most promising to increase the corrosion properties of PEO treated samples because of the formation of a homogeneous sealing layer, mainly composed of $\mathrm{La}(\mathrm{OH})_{3}$.

\section{Introduction}

The use of magnesium alloys in engineering applications has increased steadily in recent years as magnesium alloys exhibit an attractive combination of low density and high strengthweight ratio $[1,2]$.

The main problems that affect these alloys are low wear resistance and poor corrosion resistance, primarily attributed to the high chemical activity of magnesium and to the unstable imperfect natural oxide film on its surface $[3,4]$.

A lot of surface treatments have been tested in order to increase the corrosion resistance of magnesium alloys and among these plasma electrolytic oxidation (PEO) process seems to be one of the most promising processes due to the environmental friendly nature of the electrolyte and due to the good properties of the obtained coatings.

PEO of metals is a complex process that combines oxide film formation, dissolution, and dielectric breakdown and it is developed from the traditional anodic oxidation: the sample (anode) is immersed in an electrolyte and the tank is the cathode, working with higher voltages and current densities $[5,6]$. Due to the high voltage (that has to be above the dielectric breakdown potential of the oxide layer) persistent anodic microdischarges are formed on the surface during the PEO treatment. These short-lived microdischarges are the key factors of the process; they move randomly over the processed surface and produce the growth of an oxide ceramic coating [7].

However, as reported in literature only after a sealing treatment an acceptable resistance against galvanic corrosion can be obtained on PEO coated and anodized samples [8]. One of the possibilities to seal the pores that characterized the PEO coated surfaces is to produce on the coated samples a conversion coating in order to not only seal the pores but also to introduce on the coating compounds that can increase the corrosion resistance.

Conversion coatings, are commonly applied to magnesium alloys in order to increase the corrosion resistance. Such processes vary from the widely used chromate/manganese dip treatment to anodic treatments in fluoride-containing baths [9]. However, the research for more environmentally acceptable alternatives in surface modification processes has led to the identification of rare earth metal salts as good alternatives to chromate [10-14]. 
TABLE 1: Chemical composition of AZ91 magnesium alloy (wt\%).

\begin{tabular}{lcccccc}
\hline $\mathrm{Mg}$ & $\mathrm{Al}$ & $\mathrm{Zn}$ & $\mathrm{Si}$ & $\mathrm{Mn}$ & $\mathrm{Fe}$ & \\
\hline 90.8 & $8.5-9.5$ & $0.45-0.90$ & 0.35 & 0.18 & 0.014 & \\
\hline
\end{tabular}

The use of rare earth metals salts in the PEO process has been already reported in literature. In detail, one work reported the direct dissolution of lanthanum compounds in the electrolyte used to produce PEO coatings [15] and particles of insoluble cerium oxide were also used suspended in the electrolyte to obtain their coprecipitation during PEO process and improve the properties of the oxide layer $[16,17]$. Cerium salts were also used to produce solutions used as posttreatment to seal the characteristic pores on coatings obtained by PEO [18]. However, no significant studies regarding Labased post-treatments on PEO coated samples have been performed.

In this work, a La-based sealing post-treatment for environmentally friendly PEO coatings deposited on AZ91 magnesium alloy was developed. In detail, both the corrosion resistance and the surface modification produced by the posttreatment on the PEO treated samples were characterized by electrochemical and microscopic analysis. Moreover, the effect of the sealing treatment time, the temperature, and the bath composition on the corrosion resistance was studied.

\section{Experimental}

Samples of AZ91 magnesium alloy (nominal composition in Table 1) were used as substrate for PEO coatings.

Before the PEO treatment the samples were properly prepared; in detail a grinding sequence with abrasive papers was followed by polishing with clothes and diamond suspension. The samples were then degreased with acetone in ultrasounds. PEO treatment was performed using as electrolyte an aqueous alkaline solution with $50 \mathrm{~g} / \mathrm{L}$ of $\mathrm{Na}_{2} \mathrm{SiO}_{3}, 40 \mathrm{~g} / \mathrm{L}$ of $\mathrm{NaOH}$, and $50 \mathrm{~g} / \mathrm{L}$ of $\mathrm{Na}_{5} \mathrm{P}_{3} \mathrm{O}_{10}$.

A TDK-Lambda DC power supply of $400 \mathrm{~V} / 8$ A capacity was employed in the PEO treatment using the substrate as anode and as cathode a carbon steel mesh. Treatments were performed fixing the current density at $0.5 \mathrm{~A} / \mathrm{cm}^{2}$ for 2 minutes and letting the potential free to vary. After the treatment, the samples were washed with deionized water and ethanol and then dried with compressed air. The sealing treatment was performed in an aqueous solution containing $12 \mathrm{~g} / \mathrm{L}$ of $\mathrm{La}\left(\mathrm{NO}_{3}\right)_{3}$ acidified at $\mathrm{pH} 4$ with acetic acid. Different temperatures $\left(30^{\circ} \mathrm{C}, 40^{\circ} \mathrm{C}\right.$, and $\left.50^{\circ} \mathrm{C}\right)$ and different treatment times (10 and $30 \mathrm{~min}$ ) were tested in order to determine the best process parameters. The different samples were also cut along the cross section, mounted in epoxy resin, and then polished with standard metallographic technique. A Cambridge Stereoscan 440 scanning electron microscope, equipped with a Philips PV9800 EDS, was used to analyze the surface and the cross section of treated samples in order to evaluate the morphology, thickness, and composition of the coating.

Siemens D500 X-ray diffractometer with a graphite monochromatized $\mathrm{Cu}-\mathrm{K} \alpha$ radiation source $(\lambda=0.15405 \mathrm{~nm})$ operating at $40 \mathrm{kV}$ and $30 \mathrm{~mA}$ was employed to analyze the different phases present into the coating.

Perkin-Elmer $\Phi 5600 \mathrm{ci}$ spectrometer was used for XPS measurements using nonmonochromatic $\mathrm{Al}$ radiation $(1486.6 \mathrm{eV})$ working at $250 \mathrm{~W}$. The working pressure was $<5 \cdot 10^{-8} \mathrm{~Pa}$. The spectrometer was calibrated by assuming the binding energy $(\mathrm{BE})$ of the $\mathrm{Au}_{4} \mathrm{f}_{7 / 2}$ line at $83.9 \mathrm{eV}$ with respect to the Fermi level. $0.15 \mathrm{eV}$ was the standard deviation for the $\mathrm{BE}$ values. The reported $\mathrm{BE}$ were corrected for the charging effects, assigning, in the outer layers where contamination carbon is still present, to the C1s line of carbon the BE value of $284.6 \mathrm{eV}$ [19]. Survey scans (187.85 pass energy, $1 \mathrm{eV} / \mathrm{step}, 25 \mathrm{~ms}$ per step) were obtained in the 0-1350 eV range. After a Shirley type background subtraction [20], the atomic composition was evaluated using sensitivity factors supplied by Perkin [21]. The reference handbook [21], the NIST XPS Database [22], and the references reported in [23-26] were used in order to perform the assignments of the peaks. Deconvolution of the peaks was performed with XPSpeak 4.1 software.

Potentiodynamic polarization and electrochemical impedance spectroscopy (EIS) tests at ambient temperature were performed in order to study the corrosion performances of the different samples.

The tests were performed using a saturated calomel electrode as reference electrode (SCE) and a platinum electrode as counter electrode in a solution containing $0.1 \mathrm{M} \mathrm{Na}_{2} \mathrm{SO}_{4}$ and $0.05 \mathrm{M} \mathrm{NaCl}$ to simulate an aggressive environment containing both sulphates and chlorides. For potentiodynamic polarization test an AMEL 2549 Potentiostat was used with a scan rate of $0.5 \mathrm{mV} \mathrm{s}^{-1}$.

For EIS measurements a Materials Instrument Spectrometer coupled with the AMEL 2549 Potentiostat was used employing the previous described solution. EIS measurements were performed at the value of the open circuit potential and in a frequency range between $10^{5} \mathrm{~Hz}$ and $10^{-2} \mathrm{~Hz}$ with a perturbation amplitude of $10 \mathrm{mV}$. The Z-View software was used for the fitting of impedance spectra.

Moreover, also SEM-EDS observation before and after 7 days of immersion in the same electrolyte used for the electrochemical tests was performed on the more relevant samples.

\section{Results and Discussion}

The treatments were performed working at constant current density and monitoring the potential: an increase from $80 \mathrm{~V}$ to $95 \mathrm{~V}$ was observed during the process (Figure 1).

Due to the high voltage (that has to be above the dielectric breakdown potential of the oxide layer) persistent anodic microdischarges formed on the surface during the PEO treatment. These short-lived microdischarges are the key 
TABLE 2: Values of the corrosion current density and corrosion potential for samples sealed with $12 \mathrm{~g} / \mathrm{l}$ of $\mathrm{La}\left(\mathrm{NO}_{3}\right)_{3}$ at different temperature and for different treatment times, after PEO treatment.

\begin{tabular}{lcc}
\hline & $E_{\text {corr }}(\mathrm{V})$ & $i_{\text {corr }}\left(\mathrm{A} / \mathrm{cm}^{2}\right)$ \\
\hline Untreated & -1.88 & $2.00 \times 10^{-5}$ \\
PEO & -1.87 & $1.50 \times 10^{-6}$ \\
$12 \mathrm{~g} / \mathrm{L} \mathrm{La} 30^{\circ} \mathrm{C} 10 \mathrm{~min}$ & -1.73 & $8.00 \times 10^{-7}$ \\
$12 \mathrm{~g} / \mathrm{L} \mathrm{La} 30^{\circ} \mathrm{C} 30 \mathrm{~min}$ & -1.83 & $4.00 \times 10^{-7}$ \\
$12 \mathrm{~g} / \mathrm{L} \mathrm{La} 40^{\circ} \mathrm{C} 10 \mathrm{~min}$ & -1.82 & $5.00 \times 10^{-7}$ \\
$12 \mathrm{~g} / \mathrm{L} \mathrm{La} 40^{\circ} \mathrm{C} 30 \mathrm{~min}$ & -1.69 & $2.80 \times 10^{-7}$ \\
$12 \mathrm{~g} / \mathrm{L} \mathrm{La} 50^{\circ} \mathrm{C} 10 \mathrm{~min}$ & -1.73 & $9.00 \times 10^{-7}$ \\
$12 \mathrm{~g} / \mathrm{L} \mathrm{La} 50^{\circ} \mathrm{C} 30 \mathrm{~min}$ & -1.65 & $2.80 \times 10^{-7}$ \\
\hline
\end{tabular}

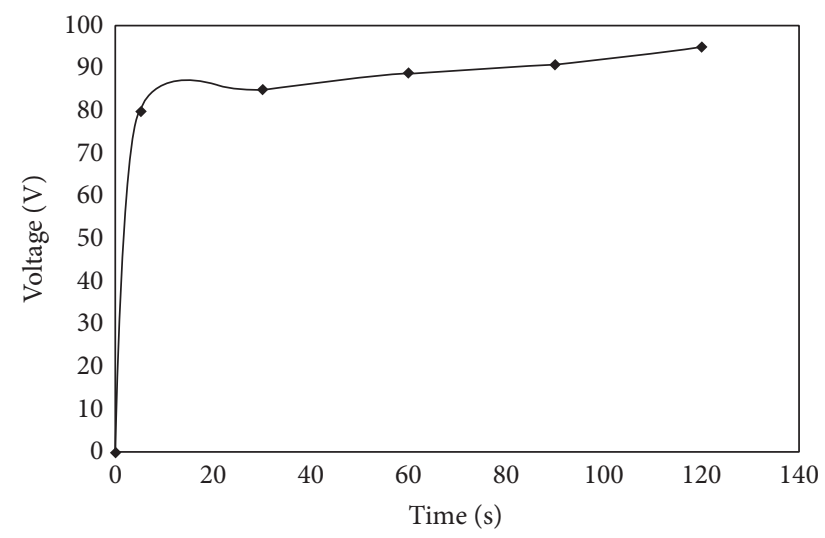

FIgURE 1: Voltage versus time plot for PEO process.

factors of the process; they move randomly over the processed surface and produce the growth of an oxide ceramic coating.

Initially, voltage linearly increased with time, corresponding to the traditional anodizing stage, in which a very thin insulating film forms. Then voltage exceeds the critical value: a large number of dispersed discharge channels are produced as a result of microregional instability caused by breakdown and, at the same time, are accompanied by a large release of oxygen. Finally, the voltage remains stable; this is known as the micro arc stage. At the end of the stage, the strong dot arc discharge appears.

\subsection{Corrosion Resistance}

3.1.1. Potentiodynamic Polarization Tests. The anodic polarization plots of the untreated sample, the PEO treated sample, and the sealed PEO treated samples are reported in Figure 2, whereas the values of the corrosion current densities $i_{\text {corr }}$ and corrosion potentials $E_{\text {corr }}$ are shown in Table 2.

As expected, PEO treatment enhanced the corrosion resistance of the alloy if compared with untreated sample, and after sealing processes a further improvement in the corrosion resistance was observed: the corrosion resistance of the sealed samples increased of one order of magnitude in comparison with the PEO treated one. From the results it can be observed that the sealing treatments performed at higher temperature and with longer treatment times induced

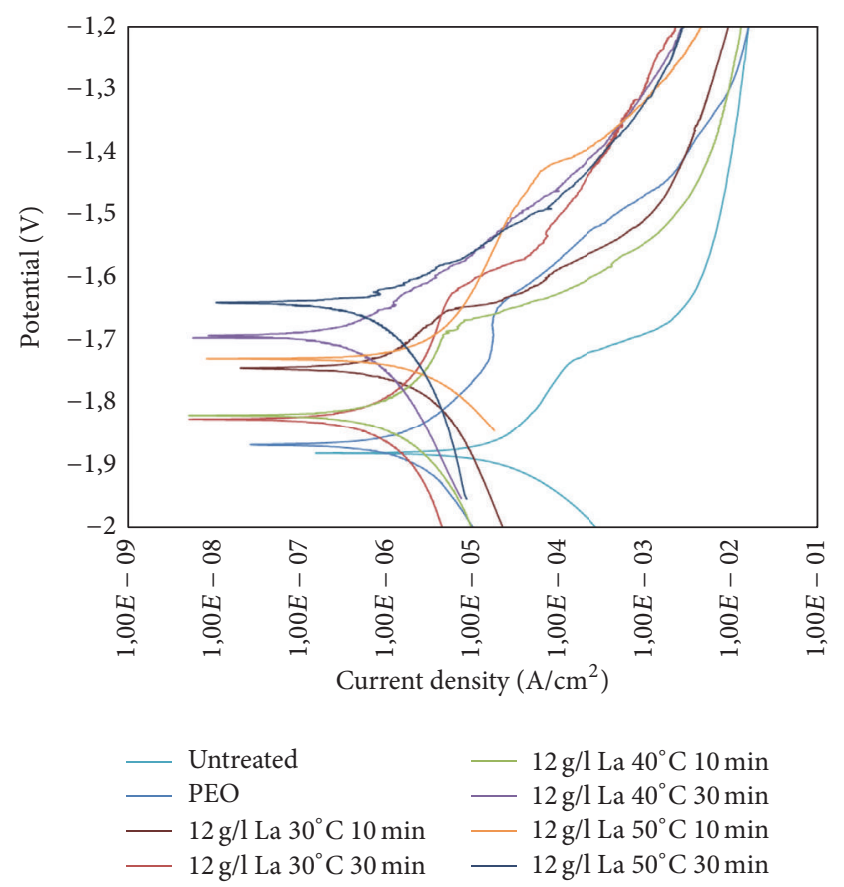

FIGURE 2: Potentiodynamic polarization plot of AZ91 magnesium alloy PEO coated at $0.5 \mathrm{~A} / \mathrm{cm}^{2}$ and sealed with $12 \mathrm{~g} / \mathrm{l}$ of $\mathrm{La}\left(\mathrm{NO}_{3}\right)_{3}$ with different treatment times and temperature.

a decrease of the corrosion current density. All samples sealed with $12 \mathrm{~g} / \mathrm{l}$ of lanthanum nitrate have a corrosion current density of the order of $10^{-7}$, but the ones sealed at higher temperature and for longer treatment times have also a higher corrosion potential. The samples treated with $12 \mathrm{~g} / \mathrm{L}$ of $\mathrm{La}\left(\mathrm{NO}_{3}\right)_{3}$ at $50^{\circ} \mathrm{C}$ for $30 \mathrm{~min}$ and at $40^{\circ} \mathrm{C}$ for $30 \mathrm{~min}$ showed the same corrosion current density $\left(2.80 \times 10^{-7} \mathrm{~A} / \mathrm{cm}^{2}\right)$ and similar corrosion potential (resp., $-1.65 \mathrm{~V}$ and $-1.69 \mathrm{~V}$ ). The samples obtained at $50^{\circ} \mathrm{C}$ after 30 minutes were characterized by the lower corrosion resistance and the nobler value of the corrosion potential. Temperatures higher than $50^{\circ} \mathrm{C}$ and longer treatment times than 30 min were also tested, but they did not provide satisfactory results.

3.1.2. Open Circuit Voltage Measurement. The open circuit voltage measurement in time of the untreated sample, the 
TABLE 3: Equivalent circuit data for samples sealed with $12 \mathrm{~g} / \mathrm{l}$ of $\mathrm{La}\left(\mathrm{NO}_{3}\right)_{3}$ at different temperature and for different treatment times, after PEO treatment.

\begin{tabular}{|c|c|c|c|c|c|c|c|c|}
\hline & Untreated & PEO & $\begin{array}{c}12 \mathrm{~g} / \mathrm{L} \mathrm{La} \\
30^{\circ} \mathrm{C} \\
10 \mathrm{~min}\end{array}$ & $\begin{array}{c}12 \mathrm{~g} / \mathrm{L} \mathrm{La} \\
30^{\circ} \mathrm{C} \\
30 \mathrm{~min}\end{array}$ & $\begin{array}{c}12 \mathrm{~g} / \mathrm{L} \mathrm{La} \\
40^{\circ} \mathrm{C} \\
10 \mathrm{~min}\end{array}$ & $\begin{array}{c}12 \mathrm{~g} / \mathrm{L} \mathrm{La} \\
40^{\circ} \mathrm{C} \\
30 \mathrm{~min}\end{array}$ & $\begin{array}{c}12 \mathrm{~g} / \mathrm{L} \mathrm{La} \\
50^{\circ} \mathrm{C} \\
10 \mathrm{~min}\end{array}$ & $\begin{array}{c}12 \mathrm{~g} / \mathrm{L} \mathrm{La} \\
50^{\circ} \mathrm{C} \\
30 \mathrm{~min}\end{array}$ \\
\hline$R_{1}$ & 23.59 & 24.75 & 23.96 & 24.00 & 25.40 & 25.50 & 25.80 & 24.60 \\
\hline$R_{2}$ & 148.70 & 1489.00 & 52.98 & 25.00 & 235.00 & 253.00 & 776.00 & 550.00 \\
\hline$R_{3}$ & - & 2672.00 & 4978.00 & 6000.00 & 6264.00 & 5106.00 & 5623.00 & 4944.00 \\
\hline$R_{4}$ & - & - & 1178.00 & 534.00 & 800.00 & 7654.00 & 8134.00 & 10305.00 \\
\hline$Q_{1}$ & $7.90 \times 10^{-6}$ & $6.20 \times 10^{-5}$ & $1.60 \times 10^{-6}$ & $2.70 \times 10^{-6}$ & $1.60 \times 10^{-5}$ & $3.37 \times 10^{-5}$ & $2.30 \times 10^{-5}$ & $2.44 \times 10^{-5}$ \\
\hline$n_{1}$ & 0.96 & 0.86 & 0.85 & 0.74 & 0.66 & 0.76 & 0.66 & 0.65 \\
\hline$Q_{2}$ & - & $1.36 \times 10^{-5}$ & $3.80 \times 10^{-5}$ & $4.43 \times 10^{-5}$ & $1.60 \times 10^{-5}$ & $7.60 \times 10^{-6}$ & $2.20 \times 10^{-6}$ & $1.33 \times 10^{-6}$ \\
\hline$n_{2}$ & - & 0.83 & 0.81 & 0.83 & 0.76 & 0.99 & 0.81 & 0.74 \\
\hline$Q_{3}$ & - & - & $1.10 \times 10^{-6}$ & $2.36 \times 10^{-5}$ & $9.80 \times 10^{-5}$ & $7.68 \times 10^{-5}$ & $4.13 \times 10^{-5}$ & $4.14 \times 10^{-7}$ \\
\hline$n_{3}$ & - & - & 0.96 & 0.84 & 0.74 & 0.86 & 0.86 & 0.86 \\
\hline Chi squared & 0.0001 & 0.0003 & 0.0003 & 0.0001 & 0.0007 & 0.0001 & 0.0002 & 0.0002 \\
\hline
\end{tabular}

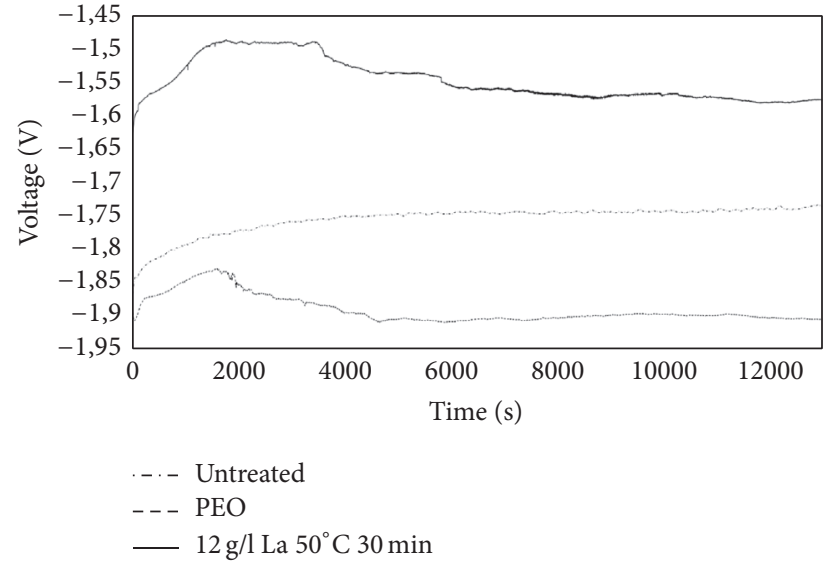

FIGURE 3: Open circuit voltage decay test for untreated sample, PEO coated sample, and best performance sealed sample.

PEO treated one, and the sealed PEO treated sample are shown in Figure 3 where it is possible to observe that the values of the potential stabilized after $1 \mathrm{~h}$ and then they remained steady; in particular, in the sample sealed with $12 \mathrm{~g} / \mathrm{L}$ of $\mathrm{La}\left(\mathrm{NO}_{3}\right)_{3}$ at $50^{\circ} \mathrm{C}$ for $30 \mathrm{~min}$, after a slight growth the potential stabilized around the $-1.55 \mathrm{~V}$ value. This suggested that these process parameters allowed the formation of a sealed coating stable in time and with good resistance properties.

3.1.3. Electrochemical Impedance Spectroscopy. EIS tests were also performed to better understand the corrosion behavior of the different samples. The experimental data were fitted with $\mathrm{Z}$-view software, using the equivalent circuits reported in Figure 4. To analyze the untreated sample the $R / C P E$ circuit was chosen (Figure 4(a)) due to the only presence of the natural oxide layer. Considering the circuit reported in Figure 4(b), this is the one often used for PEO coated samples, because it permits considering the presence of two different layers: an external porous layer and an internal barrier layer. Finally, circuit reported in Figure 4(c) was used for the sealed samples, since the layer formed by La overlaps those already present, increasing the polarization resistance. The choice of the equivalent circuits was performed in accordance with the literature regarding sealed PEO coatings [18].

Considering the correspondences between the different electrical parameters reported in the circuits and the different elements in the corrosion system the resistance of the solution is represented by $R_{1}$, the polarization resistance of the porous layer by $R_{2}$, the polarization resistance of the barrier layer by $R_{3}$, and the polarization resistance of the sealing layer by $R_{4}$. CPE $i$ are constant phase elements used in the equivalent circuit instead of capacitances in order to consider that the measured capacitance is not ideal.

The impedance representation of CPE is given by

$$
Z(\mathrm{CPE})=\frac{1}{Q(j \omega)^{n}} .
$$

In the reported formula $Q$ is a constant phase element and $\omega$ is the angular frequency; instead the number $n$ is an empirical exponent that can vary between 1 (perfect capacitor) and 0 (perfect resistor).

Nyquist impedance plots and results of the fitting of the experimental are reported in Figure 5 and Table 3 . The points in the graph represent the experimental results, whereas the continuous lines indicate the relative fitting. The agreement between experimental values and the fitting ones are good with a percentage error for the single parameters between 0.5 and $1 \%$.

For the untreated sample only $R_{1}, R_{2}, Q_{1}$, and $n_{1}$ are reported, since for the fitting a simpler circuit was used. For the PEO treated samples the values of $R_{2}$ and $R_{3}$ allowed evaluating the resistance of the porous and barrier layer, respectively, whereas for sealed samples also $R_{4}$ was considered as it indicates the polarization resistance due to the external sealing layer.

It can be observed that the sample with the highest value of $R_{4}$ and so with the highest polarization resistance is the 


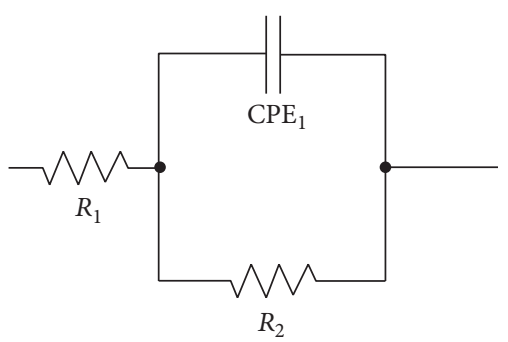

(a)

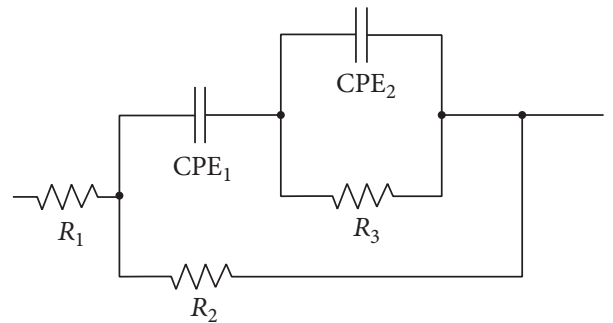

(b)

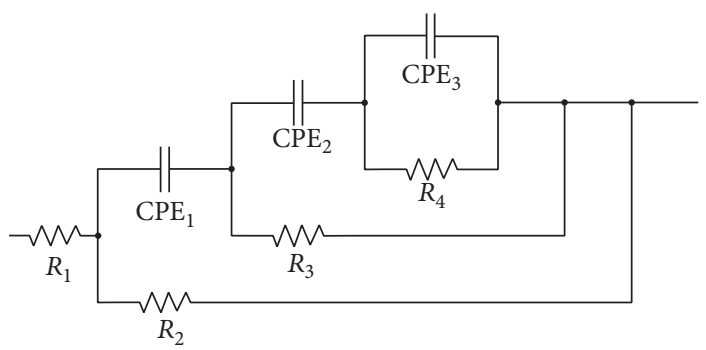

(c)

FIGURE 4: Equivalent circuits employed for curve fitting for the untreated sample (a), PEO coated sample (b), and sealed samples (c).

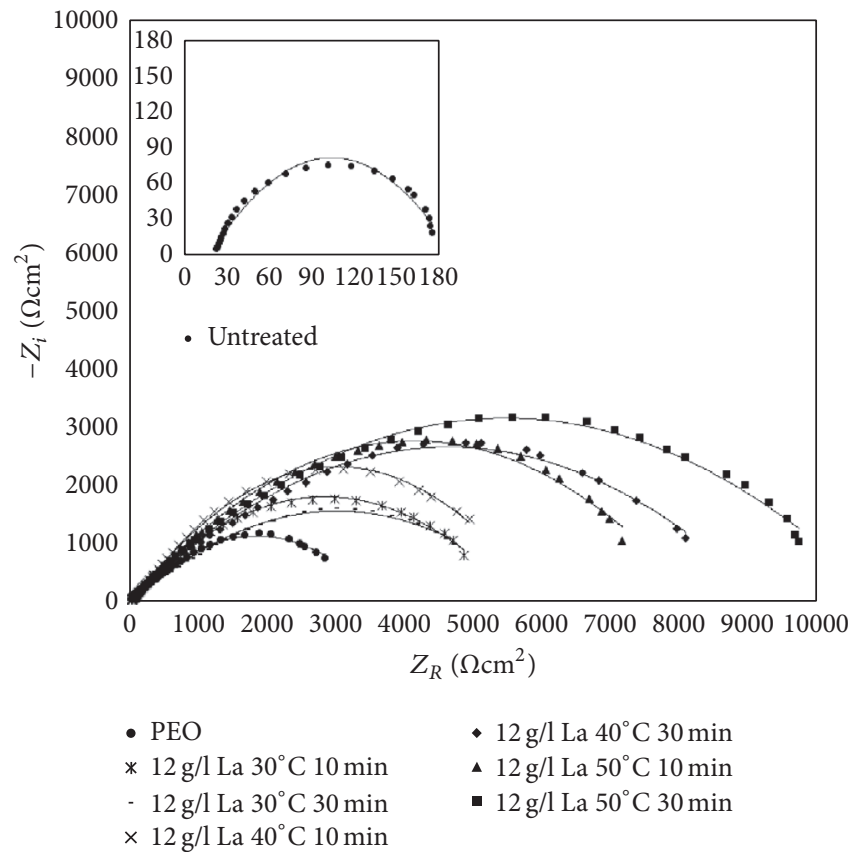

FIgURE 5: Nyquist plot of AZ91 magnesium alloy PEO coated at $0.5 \mathrm{~A} / \mathrm{cm}^{2}$ and sealed with $12 \mathrm{~g} / \mathrm{l}$ of $\mathrm{La}\left(\mathrm{NO}_{3}\right)_{3}$ with different treatment times and temperature.

one sealed with $12 \mathrm{~g} / \mathrm{L}$ of $\mathrm{La}\left(\mathrm{NO}_{3}\right)_{3}$ at $50^{\circ} \mathrm{C}$ for $30 \mathrm{~min}$, in agreement with the results of the anodic polarization tests. In both the sample treated at $30^{\circ} \mathrm{C}$ and the one treated at $40^{\circ} \mathrm{C}$ for $10 \mathrm{~min}, R_{3}$ is higher than $R_{4}$ : this suggests that in these cases the corrosion resistance is mainly due to the barrier layer, because the sealing layer was probably not uniform on the surface. Instead, the sample treated at $40^{\circ} \mathrm{C}$ and $50^{\circ} \mathrm{C}$ for 30 was characterized by values of $R_{4}$ higher than $R_{3}$, because the sealing layer provided a more corrosion resistance. The improvement in the corrosion performances after the PEO treatment is comparable with the one reported in literature regarding this kind of treatments performed on magnesium alloys [8]. In fact a remarkable increase in the corrosion properties can be obtained also without a post-treatment. The behavior after the sealing with lanthanum-containing solutions is also similar if not better in comparison with the one reported in literature after the sealing with ceriumcontaining solution [18]. The sealing treatment obtained 

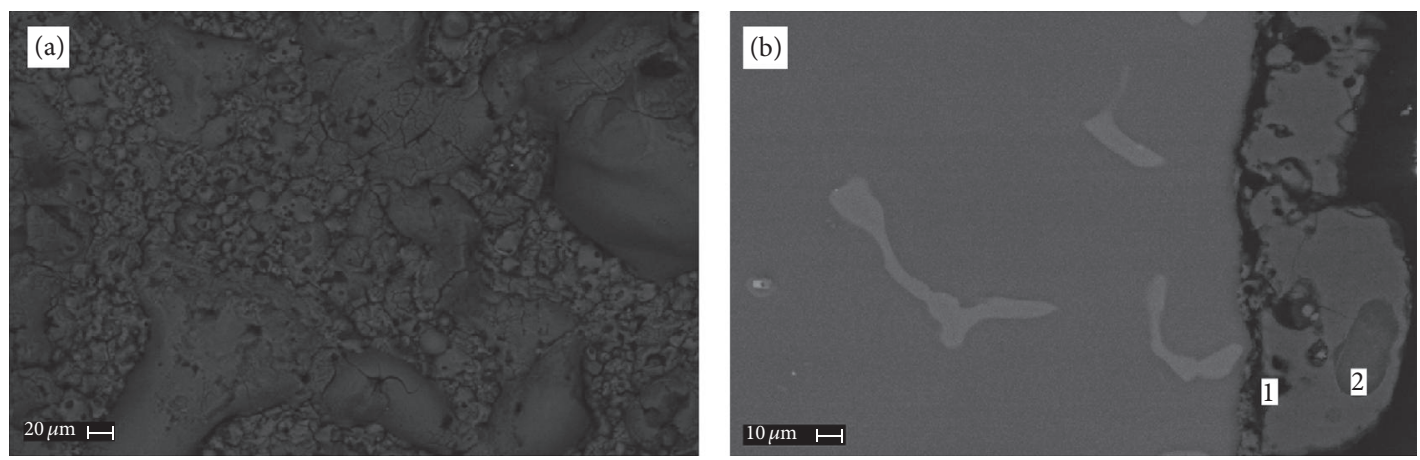

FIGURE 6: Scanning electron micrographs (backscattered electrons) of the surface and cross section of PEO coating formed on AZ91 magnesium alloy. The sample was treated at $0.5 \mathrm{~A} / \mathrm{cm}^{2}$ for 2 minutes in an aqueous alkaline solution with $50 \mathrm{~g} / \mathrm{l} \mathrm{of} \mathrm{Na}_{2} \mathrm{SiO}_{3}, 40 \mathrm{~g} / \mathrm{l} \mathrm{of} \mathrm{NaOH}$, and $50 \mathrm{~g} / \mathrm{l}$ of $\mathrm{Na}_{5} \mathrm{P}_{3} \mathrm{O}_{10}$.
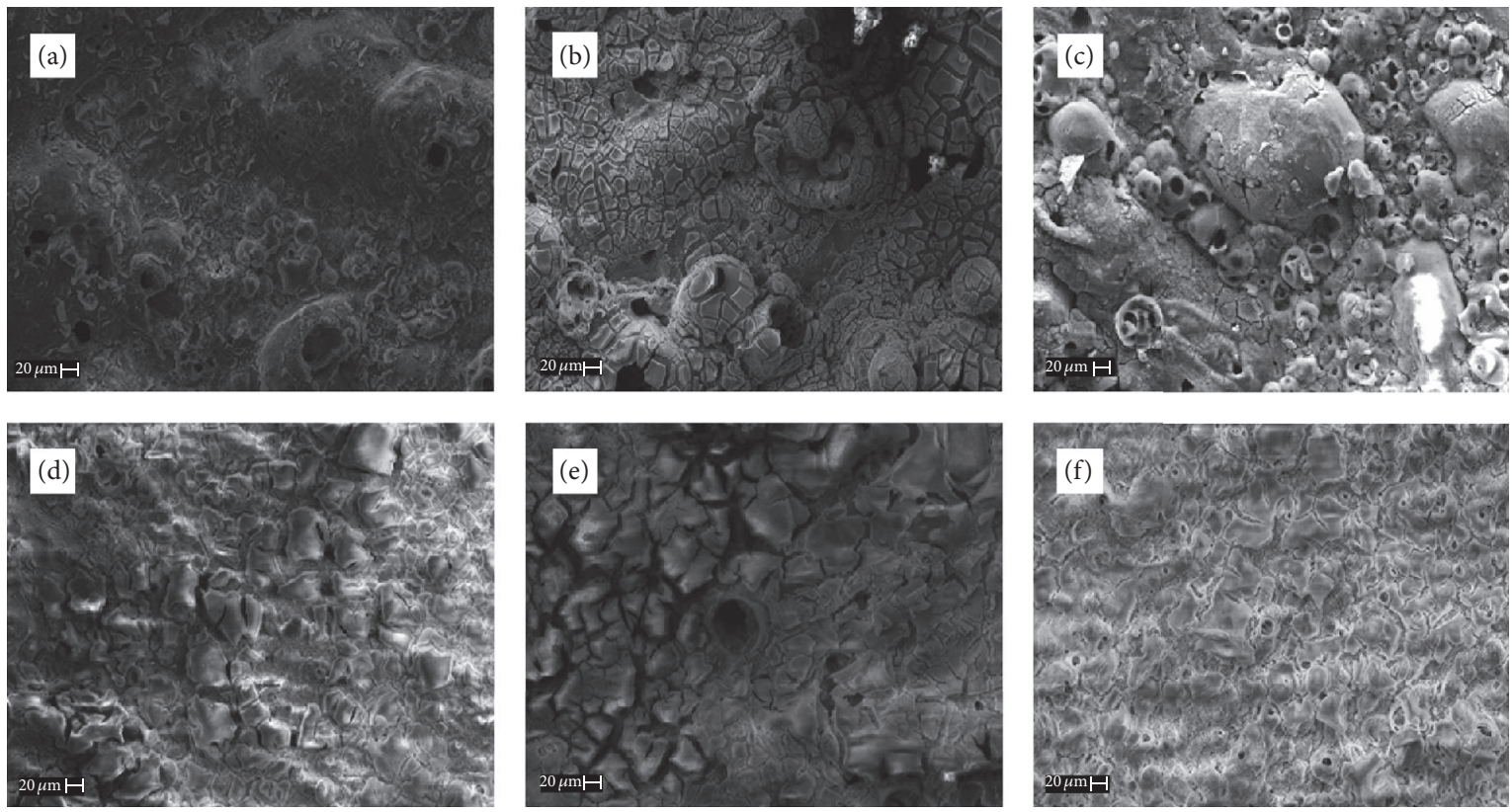

FIGURE 7: Scanning electron micrographs (secondary electrons) of the surface and cross section of sealing coatings formed on AZ91 magnesium alloy with $12 \mathrm{~g} / \mathrm{l}$ of $\mathrm{La}\left(\mathrm{NO}_{3}\right)_{3}$ with different treatment times and temperature: (a) $30^{\circ} \mathrm{C}, 10 \mathrm{~min}$; (b) $30^{\circ} \mathrm{C}, 30 \mathrm{~min}$; (c) $40^{\circ} \mathrm{C}, 10 \mathrm{~min}$; (d) $40^{\circ} \mathrm{C}, 30 \mathrm{~min}$; (e) $50^{\circ} \mathrm{C}, 10 \mathrm{~min}$; (f) $50^{\circ} \mathrm{C}, 30 \mathrm{~min}$.

with rare-earths containing solution permits significantly increasing the corrosion resistance due to both the barrier effect, given by the sealing layer, and the corrosion inhibition properties of the rare earth compound.

3.2. Surface Analysis. Surfaces and cross sections of all samples were observed by SEM with backscattered (BSE) and secondary (SE) electrons.

The morphology of surface and cross section of PEO coating is shown in Figure 6. The surface showed the typical structure of the PEO coatings with the presence of pores with different dimension and the thickness of the coating was about $30 \mu \mathrm{m}$. In the cross section image, the barrier layer (1) can be distinguished from the porous layer (2).
In Figure 7 are shown the surfaces of the sealed PEO treated samples with the different times and temperatures. Comparing the different SE-SEM images, it is possible to observe that a higher reduction of the porosity was obtained for the samples (d) and (f) that correspond to the samples sealed for $30 \mathrm{~min}$ at $40^{\circ} \mathrm{C}$ and at $50^{\circ} \mathrm{C}$, respectively. Moreover, the sample sealed at $50^{\circ} \mathrm{C}$ for 30 resulted in being more homogenous in comparison with the one obtained for the same time at $40^{\circ} \mathrm{C}$. The other sealing treatment, carried out at lower temperature and for shorter times, produced an irregular surface with the presence of large cracks and porosity. These results are in agreement with the ones obtained with the corrosion tests.

The observation with SEM using backscattered electrons allowed characterizing the distribution of lanthanum on the 

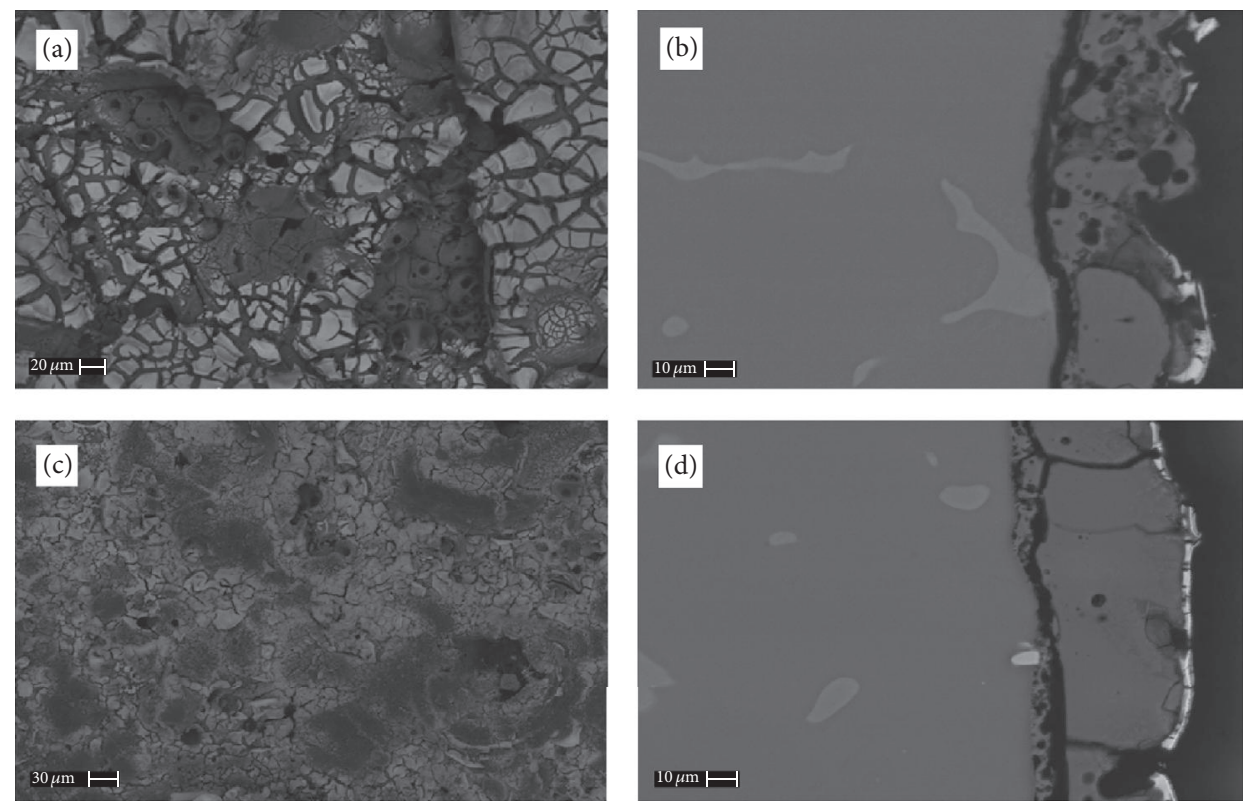

FIGURE 8: Scanning electron micrographs (backscattered electrons) of the surface and cross section of sealing coatings formed on AZ91 magnesium alloy with $12 \mathrm{~g} / \mathrm{l}$ of $\mathrm{La}\left(\mathrm{NO}_{3}\right)_{3}$ at $30^{\circ} \mathrm{C}$ for 10 minutes (a-b) and 30 minutes (c-d).
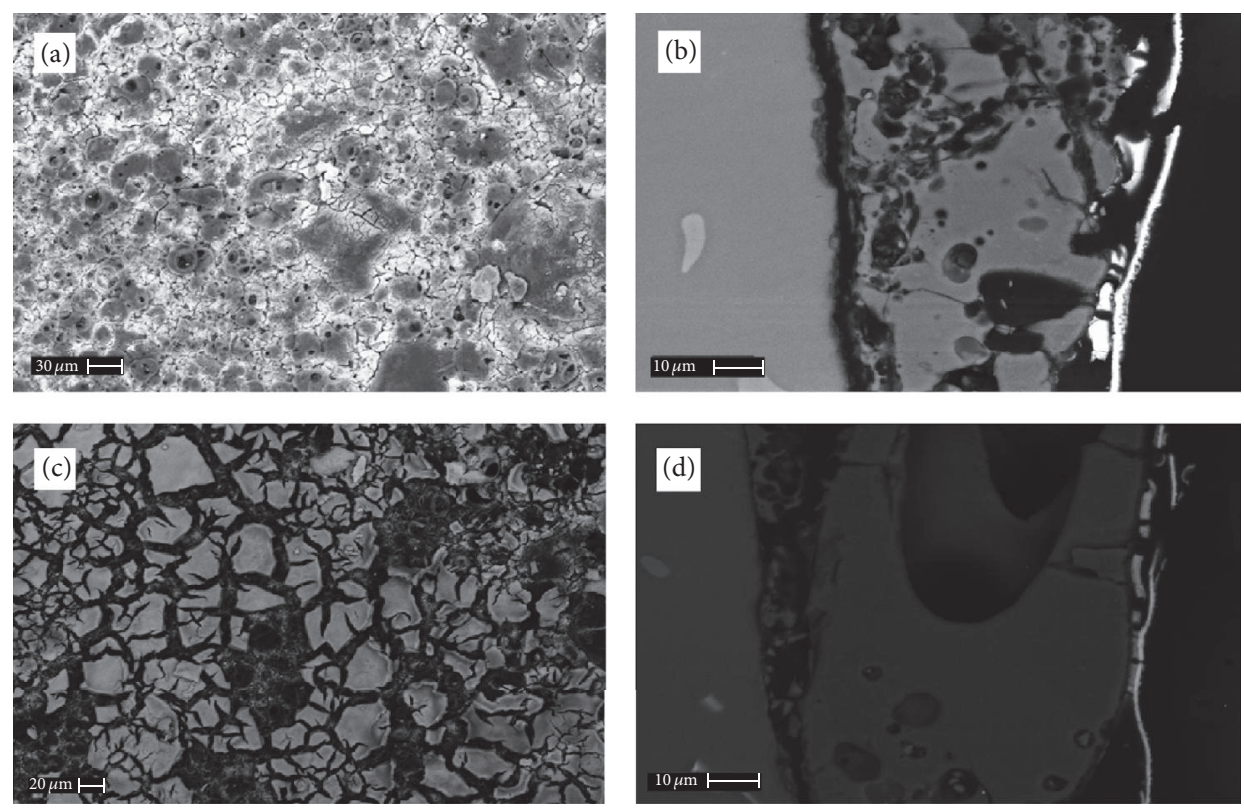

FIGURE 9: Scanning electron micrographs (backscattered electrons) of the surface and cross section of sealing coatings formed on AZ91 magnesium alloy with $12 \mathrm{~g} / \mathrm{l}$ of $\mathrm{La}\left(\mathrm{NO}_{3}\right)_{3}$ at $40^{\circ} \mathrm{C}$ for 10 minutes (a-b) and 30 minutes (c-d).

surface to the fact that it is a heavier element and thus appears brighter in the image. On the cross section lanthanum layer covers the PEO coating and represents the brighter outer layer.

In almost all the samples the surface was characterized by two zones: one brighter and cracked, where a higher amount of lanthanum was detected by EDS analysis and the other one darker and porous with a lower concentration of La.
Generally, in the samples treated for shorter times the darker zones rich in pores were more visible and in many areas lanthanum layer is irregular and thinner than the ones treated for $30 \mathrm{~min}$. Increasing the temperature and the times of the sealing treatment the distribution of La on the surface and the La layer became more homogeneous and the porosity was drastically reduced (Figures 8-10).

The coatings obtained with the sealing treatment performed for $30 \mathrm{~min}$ at $40^{\circ} \mathrm{C}$ and $50^{\circ}$ were characterized by the 

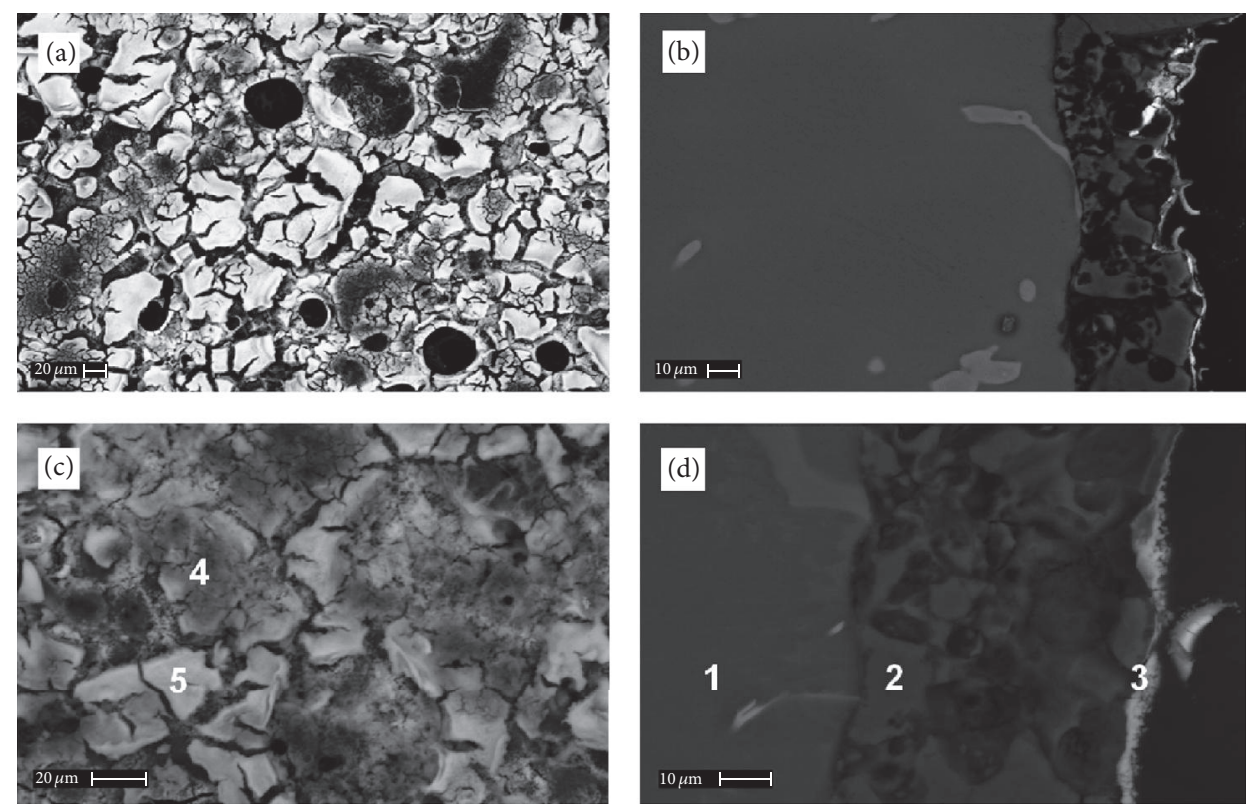

FIGURE 10: Scanning electron micrographs (backscattered electrons) of the surface and cross section of sealing coatings formed on AZ91 magnesium alloy with $12 \mathrm{~g} / \mathrm{l}$ of $\mathrm{La}\left(\mathrm{NO}_{3}\right)_{3}$ at $50^{\circ} \mathrm{C}$ for 10 minutes (a-b) and 30 minutes (c-d).

TABLE 4: Quantitative results (at \%) of EDS analysis of the cross-sectioned and surface layers.

\begin{tabular}{ccccccccc}
\hline & $\mathrm{O} \%$ & $\mathrm{Na} \%$ & $\mathrm{Mg} \%$ & $\mathrm{Al} \%$ & $\mathrm{Si} \%$ & $\mathrm{P} \%$ & $\mathrm{La} \%$ & - \\
\hline 1 & - & - & 91.65 & 8.06 & - & - & 0.29 \\
2 & 44.94 & 8.50 & 20.83 & 2.53 & 12 & 11.13 & 0.007 \\
3 & 64.21 & 5.61 & 7.9 & 1.24 & 7.91 & 3.4 & 9.73 \\
4 & 61.88 & 5.12 & 14.9 & 1.19 & 9.71 & 5.96 & 1.24 & - \\
5 & 67.97 & 2.8 & 4.33 & 0.3 & 8.14 & 2.1 & - \\
\hline
\end{tabular}

more uniform coating. Moreover, the external layer, enriched in La, was continuous and with a thickness of about $3 \mu \mathrm{m}$. This result explained the better corrosion resistance observed for these two samples during the corrosion test. It should be noted that the sample sealed at $50^{\circ} \mathrm{C}$ for $30 \mathrm{~min}$ showed a surface with a lower number of porous in comparison with the one obtained at $40^{\circ} \mathrm{C}$ for the same time, in agreement with the results obtained with the anodic polarization and EIS tests.

The EDS analysis was performed both on the surface and on the cross sections for all the sealed samples, but the results are reported only for the sample treated at $50^{\circ} \mathrm{C}$ for $30 \mathrm{~min}$. In Table 4 the elemental composition of the different points analyzed on the cross section and on the surface of the sample (Figures 10(c) and 10(d)) is reported. The analysis carried out in point 1 , which was the substrate, showed that the composition of the alloy was in agreement with the composition of the AZ91 alloy.

From the analysis performed in point 2, the PEO coating was constituted mainly by oxides of $\mathrm{Mg}, \mathrm{P}, \mathrm{Si}, \mathrm{Na}$, and $\mathrm{Al}$, in accordance with the composition of the alloy and the electrolytic solution. The outer brighter layer (point 3 ) that was the sealing coating was composed mainly of $\mathrm{O}$ and La.
The results performed on the surface in correspondence of the darker and brighter zones (points 4 and 5, resp.) clearly indicated that the composition is different in the two zones, and, as expected, the brighter zone was enriched in La, in comparison with the darker zone. The EDS analysis performed on the other samples confirmed the results reported for this one.

The XRD analysis performed on the PEO treated sample and the results can be observed in Figure 11.

The presence of $\mathrm{MgO}, \mathrm{Mg}_{3}\left(\mathrm{PO}_{4}\right)_{2}$, and $\mathrm{Mg}_{2} \mathrm{SiO}_{4}$ was in accordance with the composition of the alloy and of the electrolyte used in PEO process and in accordance with the literature [1]. The presence of the $\mathrm{Mg}$ peaks is due to the reflection from the substrate.

XPS survey scans (without sputtering) and XPS high resolution analysis were performed on the PEO treated sample and on the sealed PEO treated sample at $50^{\circ} \mathrm{C}$ for $30 \mathrm{~min}$, to investigate the chemical state of their surfaces. The survey spectra of the samples are shown in Figure 12.

From the collected spectrum of the main photoelectron lines, the atomic percentages of the elements present in the external surface of the coating were calculated. The layer of the $\mathrm{PEO}$ treated sample resulted to be principally constituted by $\mathrm{O}, \mathrm{Mg}, \mathrm{Si}, \mathrm{P}, \mathrm{Al}$, and $\mathrm{Na}$, whereas in the coating of the sealed 


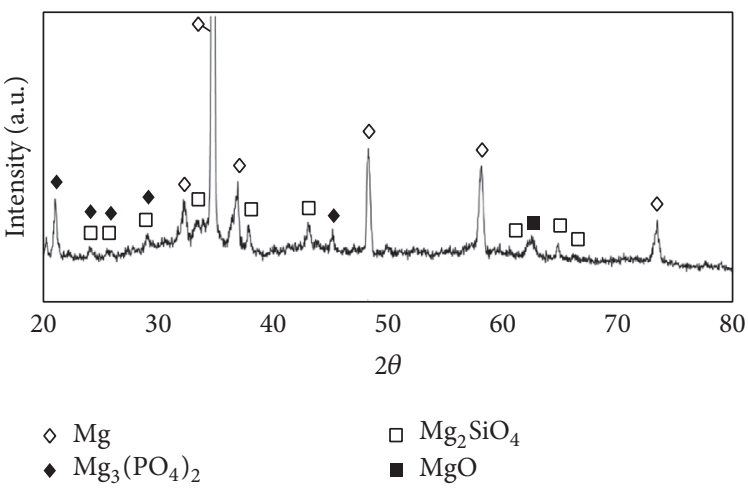

FIgURE 11: X-ray diffraction patterns for the sample of AZ91 magnesium alloy treated with PEO process at $0.5 \mathrm{~A} / \mathrm{cm}^{2}$ for 2 minutes, in an aqueous alkaline solution with $50 \mathrm{~g} / \mathrm{l}$ of $\mathrm{Na}_{2} \mathrm{SiO}_{3}, 40 \mathrm{~g} / \mathrm{l}$ of $\mathrm{NaOH}$, and $50 \mathrm{~g} / \mathrm{l}$ of $\mathrm{Na}_{5} \mathrm{P}_{3} \mathrm{O}_{10}$.

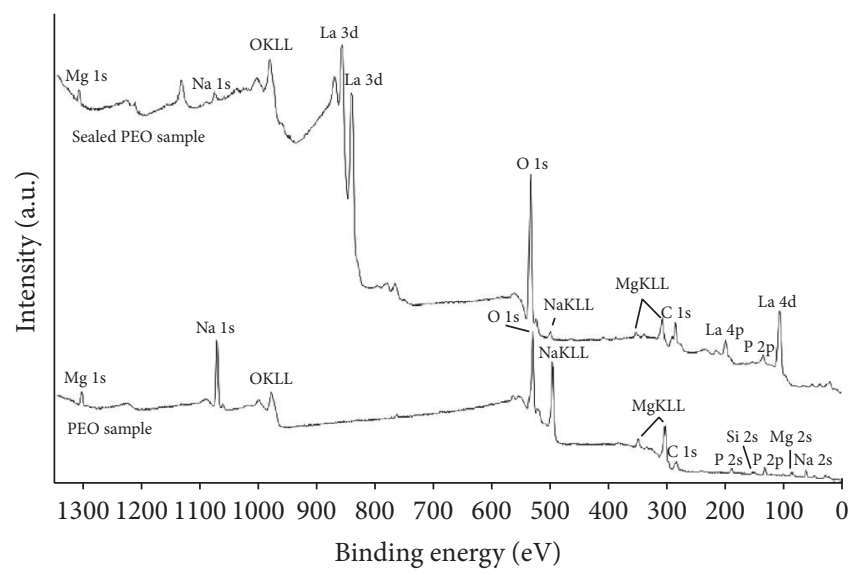

FIGURE 12: XPS survey scan for the PEO treated sample and for the sample sealed in an aqueous solution with $12 \mathrm{~g} / \mathrm{l}$ of $\mathrm{La}\left(\mathrm{NO}_{3}\right)_{3}$ at $50^{\circ} \mathrm{C}$ for 30 minutes.

PEO treated sample, besides these elements, also the presence of La was detected.

The surface of $\mathrm{PEO}$ coated sample was constituted mainly by $\mathrm{O}, \mathrm{Mg}, \mathrm{P}, \mathrm{Si}$, and $\mathrm{Na}$. The analysis of the high resolution peaks of P 2p and Si 2p (Figures 13(a) and 13(b), resp.) confirmed the results obtained in the previous works, where both silicate and phosphate were used for the PEO treatment, and the presence of $\mathrm{Mg}$ phosphate and $\mathrm{Mg}$ silicate was found in agreement also with XRD analysis. The high resolution $\mathrm{P}$ $2 \mathrm{p}$ peak is shown in Figure 13(a), where it is possible to see that the peak was separated in two peaks at 133.1 and $134 \mathrm{eV}$ that correspond to $\mathrm{P} 2 \mathrm{p}_{3 / 2}$ and $\mathrm{P} 2 \mathrm{p}_{1 / 2}$, respectively. These values are in accordance with the presence of $\left(\mathrm{PO}_{4}\right)^{3-}$ species $[21,22]$ and were attributed to the presence of $\mathrm{Mg}_{3}\left(\mathrm{PO}_{4}\right)_{2}$ and $\mathrm{Na}_{3} \mathrm{PO}_{4}$ [27]. The high resolution $\mathrm{Si} 2 \mathrm{p}$ peak is shown in Figure 13(b). It resulted from the sum of two peaks: the one situated at $101.8 \mathrm{eV} \mathrm{BE}$ attributed to the alpha $\mathrm{Mg}_{2} \mathrm{SiO}_{4}$ and the one at $102.9 \mathrm{eV} \mathrm{BE}$ corresponding to gamma $\mathrm{Mg}_{2} \mathrm{SiO}_{4}$ [15]. For each of these two peaks, also the two components $2 \mathrm{p}_{3 / 2}$ and $2 \mathrm{p}_{1 / 2}$ are shown in the figure.

In the PEO treated sample, the $\mathrm{Mg} 2$ s signal could be fitted with a component at $88.1 \mathrm{eV}$, corresponding to $\mathrm{MgO}$, and a second bigger one at $89.3 \mathrm{eV}$, corresponding to $\mathrm{Mg}_{3}\left(\mathrm{PO}_{4}\right)_{2}$ and/or $\mathrm{Mg}_{2} \mathrm{SiO}_{4}$ [21] (Figure 13(c)).

$\mathrm{Mg} 2 \mathrm{~s}$ high-resolution data were collected for both samples, but the intensity of this peak in the sealed PEO treated sample was very weak and thus could not be used to obtain any useful information. The Mg 2p-KLL Auger parameter was evaluated for the two samples and found to be almost equal (PEO: $1230.9 \mathrm{eV}$, La $1230.5 \mathrm{eV}$ ). These values are compatible with oxidized magnesium in an oxidic form, like $\mathrm{MgO}$ and/or $\mathrm{Mg}_{2} \mathrm{SiO}_{4}$.

The surface of sealed PEO treated sample was composed mainly by $\mathrm{O}$ and La. The high-resolution $\mathrm{O} 1 \mathrm{~s}$ spectra of the sealed PEO treated sample are shown in Figure 14(a); the main peak located at $531.7 \mathrm{eV} \mathrm{BE}$ corresponds to the metal hydroxides, in this case $\mathrm{La}(\mathrm{OH})_{3}$. The oxides species were not present.

The high resolution $\mathrm{La} 3 \mathrm{~d}_{5 / 2}$ region is shown in Figure 14(b), and it was possible to distinguish the presence of three peaks: the main peak located at $835.2 \mathrm{eV} \mathrm{BE}$ and the two satellite peaks at 837 and $839 \mathrm{eV} \mathrm{BE}$. The area of the main peak represents the $45 \%$ of the whole area, whereas the sum of the two satellites peaks corresponds to the remaining 55\%. The 


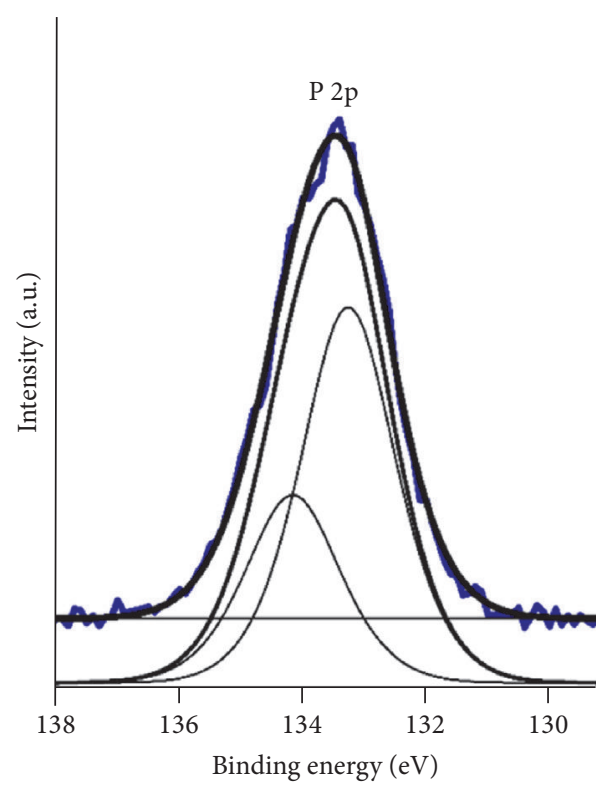

(a)

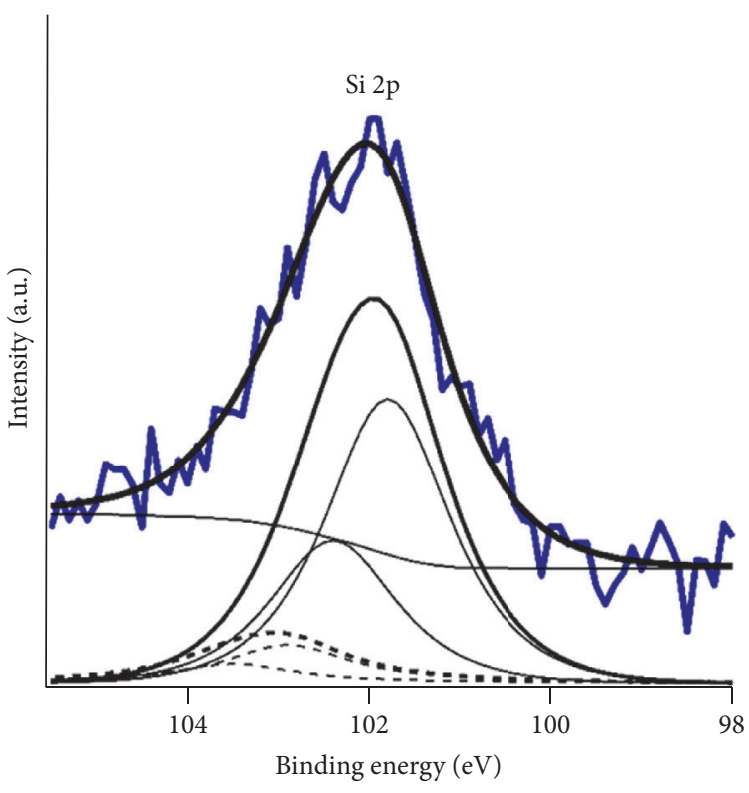

(b)

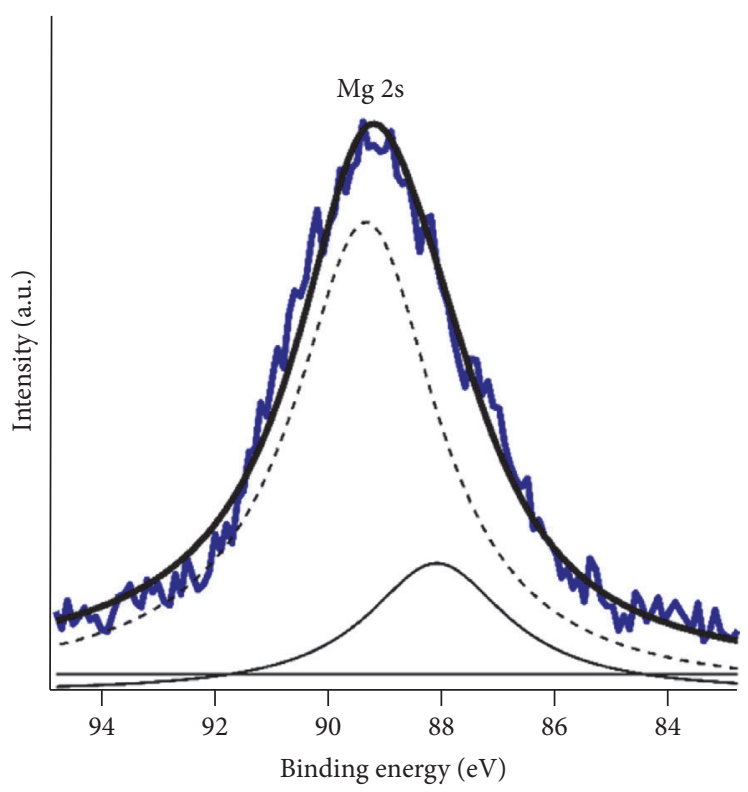

(c)

FIGURE 13: XPS high resolution single peak analysis for the P 2p peak (a), Si 2p peak (b), and Mg 2s peak (c) performed on the PEO treated sample.

ratio between the satellite peaks area and the main peak area was 1.2, indicating the presence of $\mathrm{La}(\mathrm{OH})_{3}$ [28].

Therefore, from XPS analysis, the surface of the PEO treated samples was constituted mainly by $\mathrm{Mg}_{3}\left(\mathrm{PO}_{4}\right)_{2}$, $\mathrm{Na}_{3} \mathrm{PO}_{4}$, and $\mathrm{MgSiO}_{4}$, whereas, after the treatment of sealing with La salts, it was constituted mainly by $\mathrm{La}(\mathrm{OH})_{3}$.

In order to connect the surface characterization with the corrosion analysis SEM-EDS observation on the more relevant samples before and after 7 days of immersion in a solution $0.1 \mathrm{M} \mathrm{Na}_{2} \mathrm{SO}_{4}$ and $0.05 \mathrm{M} \mathrm{NaCl}$ was performed. In particular, the sample with the best corrosion performance (sealing at $50^{\circ} \mathrm{C}$ for $30 \mathrm{~min}$ ), the sample with the worst corrosion performance after sealing $\left(30^{\circ} \mathrm{C}\right.$ for $\left.10 \mathrm{~min}\right)$, and the sample PEO treated without sealing were analyzed. The results of the SEM observation are reported in Figure 15 and the results of EDS analysis (at \%) in Table 5.

It can be clearly observed that the PEO treated sample and the one sealed at $30^{\circ} \mathrm{C}$ for $10 \mathrm{~min}$ are characterized, after 7 days of immersion, by the presence of a lot of corrosion phenomena in particular in form of cracks on the surface of the coating. The formation of cracks can be linked with the water absorption in the pores of the PEO coating and 


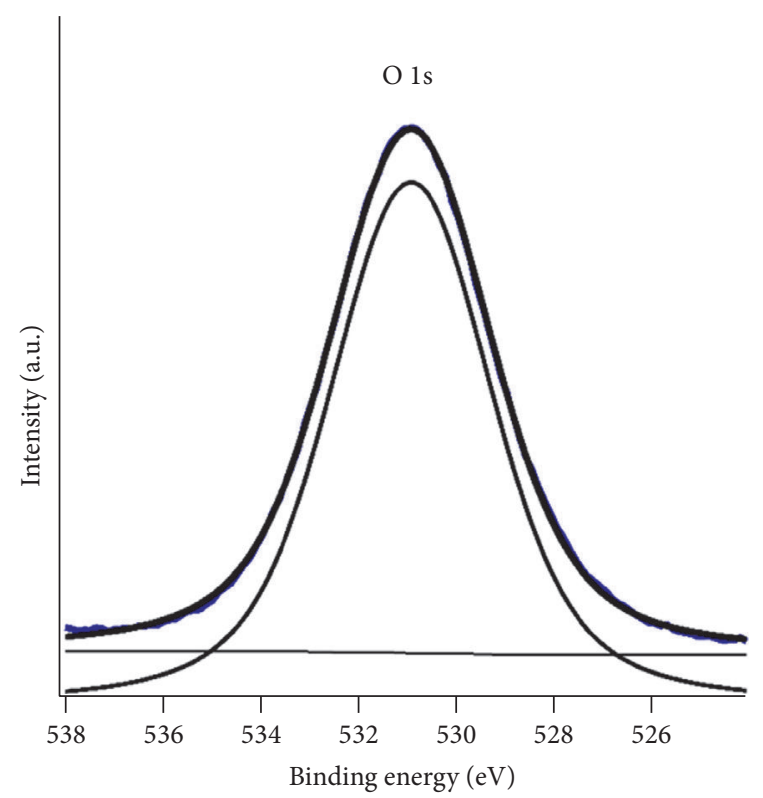

(a)

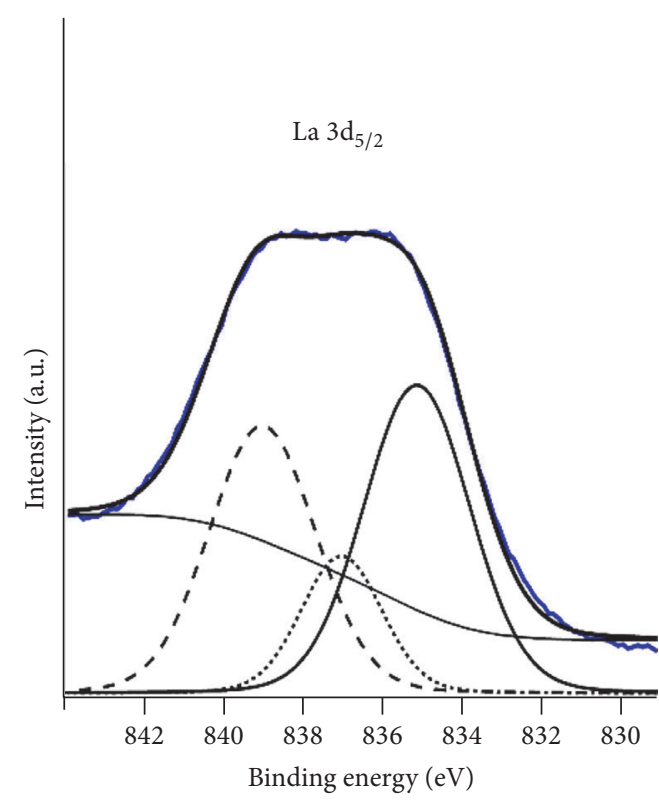

(b)

FIGURE 14: XPS high resolution single peak analysis for (a) O1s peak and (b) $\mathrm{La3d}_{5 / 2}$ peak performed on the sample sealed in an aqueous solution with $12 \mathrm{~g} / \mathrm{L}$ of $\mathrm{La}\left(\mathrm{NO}_{3}\right)_{3}$ at $50^{\circ} \mathrm{C}$ for $30 \mathrm{~min}$.

TABLE 5: Quantitative results (at \%) of EDS analysis of the samples before and after 7 days of immersion.

\begin{tabular}{lccccccccc}
\hline & $\mathrm{O} \%$ & $\mathrm{Na} \%$ & $\mathrm{Mg} \%$ & $\mathrm{Al} \%$ & $\mathrm{Si} \%$ & $\mathrm{P} \%$ & $\mathrm{La} \%$ & $\mathrm{Cl} \%$ & $\mathrm{~S} \%$ \\
\hline $\mathrm{PEO}$ & 61.04 & 2.54 & 20.21 & 0.34 & 12.42 & 3.45 & - & - & - \\
$12 \mathrm{~g} / \mathrm{l} \mathrm{La} 30^{\circ} \mathrm{C} 10 \mathrm{~min}$ & 60.62 & 2.33 & 14.91 & 0.42 & 9.61 & 3.69 & 8.42 & - & - \\
$12 \mathrm{~g} / \mathrm{l} \mathrm{La} 50^{\circ} \mathrm{C} 30 \mathrm{~min}$ & 58.69 & 3.06 & 12.43 & 0.96 & 9.42 & 4.23 & 11.21 & - \\
$\mathrm{PEO} \mathrm{Corr}$ & 64.20 & 2.00 & 19.20 & 0.3 & 9.47 & 2.50 & - & 1.1 & 1.23 \\
$12 \mathrm{~g} / \mathrm{l} \mathrm{La} 30^{\circ} \mathrm{C} 10 \mathrm{~min}$ Corr & 63.42 & 2.12 & 18.26 & 0.3 & 8.96 & 2.42 & 2.54 & 0.96 & 1.02 \\
$12 \mathrm{~g} / \mathrm{l} \mathrm{La} 50^{\circ} \mathrm{C} \mathrm{30} \mathrm{min} \mathrm{Corr}$ & 63.84 & 3.00 & 12.36 & 0.4 & 7.67 & 2.79 & 9.56 & 0.15 & 0.23 \\
\hline
\end{tabular}

the formation of corrosion products that cause an expansion and consequently the fracture of the coating. This fact is confirmed also by EDS analysis reported in Table 5 that evidences the presence of corrosion products on the surface in form of sulfates and chlorides. Moreover, also a remarkable decrease in the lanthanum presence on the surface of the sample sealed at $30^{\circ} \mathrm{C}$ for 10 min after the immersion can be recorded. This fact can be linked to the poor adhesion of the sealing layer that was observed in this sample. Instead on the surface of the sample sealed at $50^{\circ} \mathrm{C}$ for $30 \mathrm{~min}$ only a small amount of cracks due to corrosion phenomena can be observed in the SEM image. This fact can be linked with the evidence that the sealing treatment was more effective in the sample treated at $50^{\circ} \mathrm{C}$ for $30 \mathrm{~min}$ and this produces a decrease in the water absorption and the formation of corrosion products. This evidence is also confirmed by EDS analysis where reduced amount of chlorides and sulfates is measured and also the decrease in lanthanum content is less relevant in comparison to the sample sealed at $30^{\circ} \mathrm{C}$ for $10 \mathrm{~min}$. This fact is a clear evidence of the higher corrosion performances of the sample sealed at $50^{\circ} \mathrm{C}$ for $30 \mathrm{~min}$, given by the presence of a more adherent and uniform lanthanumcontaining sealing layer.

\section{Conclusion}

In this work samples of AZ91 magnesium alloy were treated with PEO process, working with high current densities and short treatment times, using as electrolyte a base alkaline solution containing sodium hydroxide and sodium silicate. Then the porous surface of these samples was sealed with an aqueous solution containing lanthanum nitrate: this sealing process improved the corrosion resistance of PEO coated samples. The working temperature and the treatment times used influenced the corrosion resistance and surface morphology. Working with higher temperatures and longer treatment times produced an increase in the corrosion performances of the coated samples, as shown from the results of anodic polarization and EIS tests. The OCV tests showed also that the sealing process provided a long lifetime to the treated samples. 

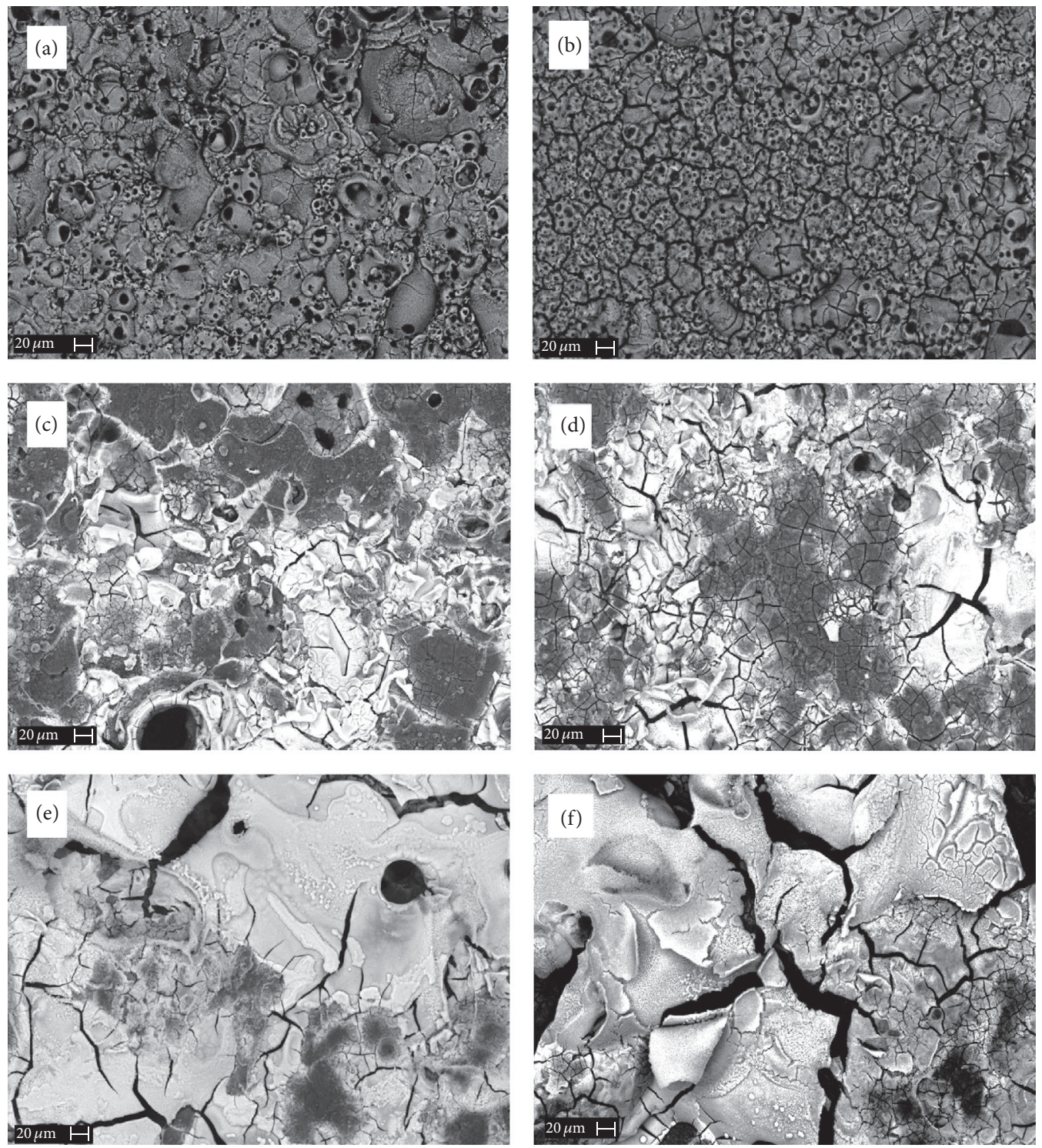

FIGURE 15: Scanning electron micrographs (backscattered electrons) of the surface of the samples before and after 7 days of immersion. In detail PEO treated before (a) and after (b) immersion, sealed at $30^{\circ} \mathrm{C}$ for $10 \mathrm{~min}$ before (c) and after (d) immersion, and sealed at $50^{\circ} \mathrm{C}$ for 30 min before (e) and after (f) immersion.

The improvement in the corrosion performances can be correlated with the formation of an external lanthanum layer: this layer became more uniform and adherent with the PEO layer increasing the working temperature and treatment time of sealing process. The sample characterized by the highest corrosion resistance was obtained with $12 \mathrm{~g} / \mathrm{L}$ of $\mathrm{La}\left(\mathrm{NO}_{3}\right)_{3}$ at $50^{\circ} \mathrm{C}$ for $30 \mathrm{~min}$. This fact was confirmed also by immersion test for 7 days in aggressive environment.

The protective layer obtained with the sealing process was mainly composed of $\mathrm{La}(\mathrm{OH})_{3}$.

In conclusion the sealing process of the porous $\mathrm{PEO}$ layer improved the corrosion resistance of AZ91 magnesium alloy, decreasing the corrosion current density up to two orders of magnitude and slightly increasing the corrosion potential.

\section{Competing Interests}

The authors declare that there is no conflict of interests regarding the publication of this paper.

\section{Acknowledgments}

ICMATE-CNR (Padova) is gratefully acknowledged for financial support and provision of XPS equipment. The authors would like to thank Dr. S. Gross (ICMATE-CNR) for helpful discussion.

\section{References}

[1] J. Liang, P. Bala Srinivasan, C. Blawert, M. Störmer, and W. Dietzel, "Electrochemical corrosion behaviour of plasma electrolytic 
oxidation coatings on AM50 magnesium alloy formed in silicate and phosphate based electrolytes," Electrochimica Acta, vol. 54, no. 14, pp. 3842-3850, 2009.

[2] B. L. Mordike and T. Ebert, "Magnesium properties-applications-potential," Materials Science and Engineering A, vol. 302, no. 1, pp. 37-45, 2001.

[3] L. Wang, L. Chen, Z.-C. Yan, H.-L. Wang, and J.-Z. Peng, "Growth and corrosion characteristics of plasma electrolytic oxidation ceramic films formed on AZ31 magnesium alloy," The Chinese Journal of Process Engineering, vol. 9, no. 3, pp. 592-597, 2009.

[4] G. Song and A. Atrens, "Understanding magnesium corrosion-a framework for improved alloy performance," Advanced Engineering Materials, vol. 5, no. 12, pp. 837-858, 2003.

[5] L. O. Snizhko, A. L. Yerokhin, A. Pilkington et al., "Anodic processes in plasma electrolytic oxidation of aluminium in alkaline solutions," Electrochimica Acta, vol. 49, no. 13, pp. 20852095, 2004.

[6] F.-H. Cao, L.-Y. Lin, Z. Zhang, J.-Q. Zhang, and C.-N. Cao, "Environmental friendly plasma electrolytic oxidation of AM60 magnesium alloy and its corrosion resistance," Transactions of Nonferrous Metals Society of China, vol. 18, no. 2, pp. 240-247, 2008.

[7] J. Martin, A. Melhem, I. Shchedrina et al., "Effects of electrical parameters on plasma electrolytic oxidation of aluminium," Surface and Coatings Technology, vol. 221, pp. 70-76, 2013.

[8] C. Blawert, W. Dietzel, E. Ghali, and G. Song, "Anodizing treatments for magnesium alloys and their effect on corrosion resistance in various environments," Advanced Engineering Materials, vol. 8, no. 6, pp. 511-533, 2006.

[9] E. F. Emley, Principles of Magnesium Technology, Pergamon Press, Oxford, UK, 1966.

[10] A. L. Rudd, C. B. Breslin, and F. Mansfeld, "The corrosion protection afforded by rare earth conversion coatings applied to magnesium," Corrosion Science, vol. 42, no. 2, pp. 275-288, 2000.

[11] A. Pardo, M. C. Merino, R. Arrabal, S. Merino, F. Viejo, and A. E. Coy, "Effect of La surface treatments on corrosion resistance of $\mathrm{A} 3 \times x . x / \mathrm{SiC}_{p}$ composites in salt fog," Applied Surface Science, vol. 252, no. 8, pp. 2794-2805, 2006.

[12] L. Yang, J. Li, X. Yu, M. Zhang, and X. Huang, "Lanthanumbased conversion coating on Mg-8Li alloy," Applied Surface Science, vol. 255, no. 5, pp. 2338-2341, 2008.

[13] L. Yang, J. Li, C. Lin, M. Zhang, and J. Wu, "Study of molybdenum/lanthanum-based composite conversion coatings on AZ31 magnesium alloy," Applied Surface Science, vol. 257, no. 7, pp. 2838-2842, 2011.

[14] C. Lin, C. Changguo, W. Ningning, W. Jimin, and D. Ling, "Study of cerium and lanthanum conversion coatings on AZ63 magnesium alloy surface," Rare Metal Materials and Engineering, vol. 44, no. 2, pp. 333-338, 2015.

[15] L. Pezzato, K. Brunelli, and M. Dabalà, "Corrosion properties of plasma electrolytic oxidation coated AA7075 treated using an electrolyte containing lanthanum-salts," Surface and Interface Analysis, vol. 48, no. 8, pp. 729-738, 2016.

[16] S. A. Salman, R. Ichino, and M. Okido, "Improvement of corrosion resistance of AZ31 Mg alloy by anodizing with coprecipitation of cerium oxide," Transactions of Nonferrous Metals Society of China, vol. 19, no. 4, pp. 883-886, 2009.
[17] T. S. Lim, H. S. Ryu, and S.-H. Hong, "Electrochemical corrosion properties of $\mathrm{CeO}_{2}$-containing coatings on AZ31 magnesium alloys prepared by plasma electrolytic oxidation," Corrosion Science, vol. 62, pp. 104-111, 2012.

[18] M. Mohedano, C. Blawert, and M. L. Zheludkevich, "Ceriumbased sealing of PEO coated AM50 magnesium alloy," Surface and Coatings Technology, vol. 269, no. 1, pp. 145-154, 2015.

[19] M. P. Seah, D. Briggs, and J. Seah, Practical Surface Analysis, Auger and X-ray Photoelectron Spectroscopy, 1, 543, 1990.

[20] D. A. Shirley, "High-resolution X-ray photoemission spectrum of the valence bands of gold," Physical Review B, vol. 5, no. 12, pp. 4709-4714, 1972.

[21] J. F. Moulder, W. F. Stickle, P. E. Sobol, K. D. Bomben, and J. Chastain, Handbook of X-Ray Photoelectron Spectroscop, Perkin Elemer Corp, Eden Prairie, Minn, USA, 1992.

[22] X-ray Photoelectron Spectroscopy Database 20, Version 3.0, National Institute of Standards and Technology, Gaithersburg.

[23] A. Glisenti, A. Frasson, A. Galenda, and M. Maria Natile, "Au/ $\mathrm{CeO} 2$ supported nanocatalysts: interaction with methanol," Nanoscience and Nanotechnology Letters, vol. 2, no. 3, pp. 213219, 2010.

[24] M. M. Natile, F. Tomaello, and A. Glisenti, " $\mathrm{WO}_{3} / \mathrm{CeO}_{2}$ nanocomposite powders: synthesis, characterization, and reactivity," Chemistry of Materials, vol. 18, no. 14, pp. 3270-3280, 2006.

[25] Y. A. Teterin, A. Y. Teterin, A. M. Lebedev, and I. O. Utkin, "The XPS spectra of cerium compounds containing oxygen," Journal of Electron Spectroscopy and Related Phenomena, vol. 88-91, pp. 275-279, 1998.

[26] S. Wang, Z. Qiao, W. Wang, and Y. Qian, "XPS studies of nanometer $\mathrm{CeO} 2$ thin films deposited by pulse ultrasonic spray pyrolysis," Journal of Alloys and Compounds, vol. 305, no. 1-2, pp. 121-124, 2000.

[27] Y. Mori, A. Koshi, J. LIao, H. Asoh, and S. Ono, "Characteristics and corrosion resistance of plasma electrolytic oxidation coatings on AZ31B Mg alloy formed in phosphate-silicate mixture electrolytes," Corrosion Science, vol. 88, pp. 254-262, 2014.

[28] M. F. Sunding, K. Hadidi, S. Diplas, O. M. Løvvik, T. E. Norby, and A. E. Gunnæs, "XPS characterisation of in situ treated lanthanum oxide and hydroxide using tailored charge referencing and peak fitting procedures," Journal of Electron Spectroscopy and Related Phenomena, vol. 184, no. 7, pp. 399-409, 2011. 

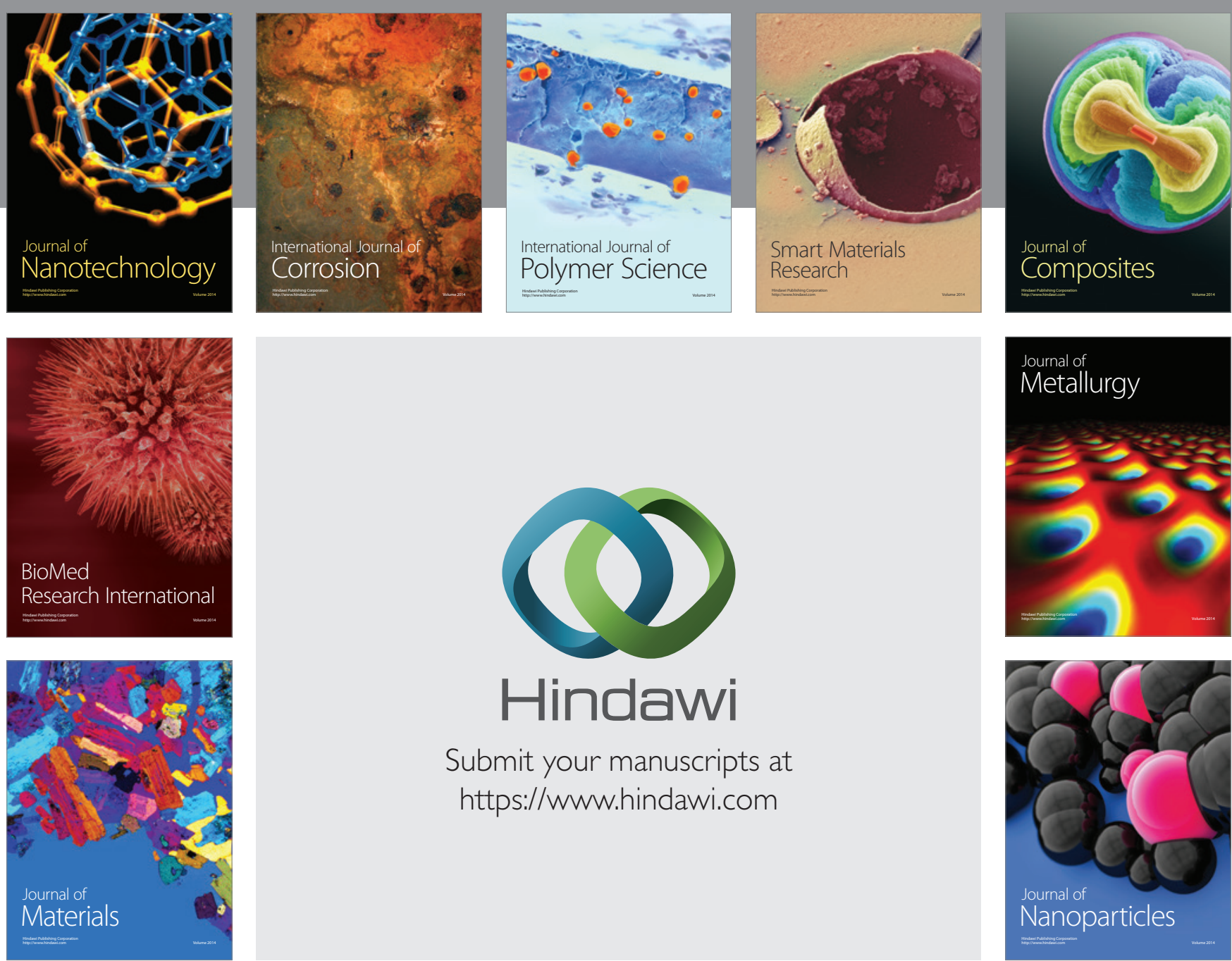

\section{Hindawi}

Submit your manuscripts at

https://www.hindawi.com

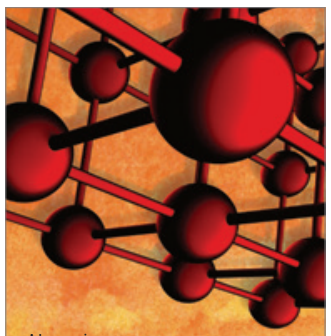

Materials Science and Engineering
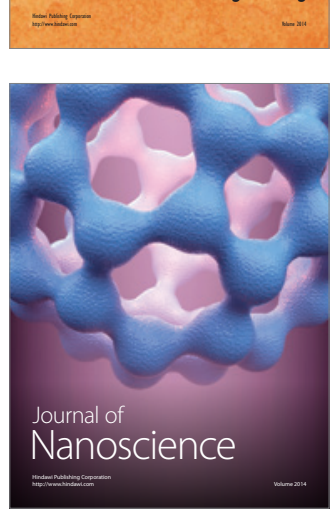
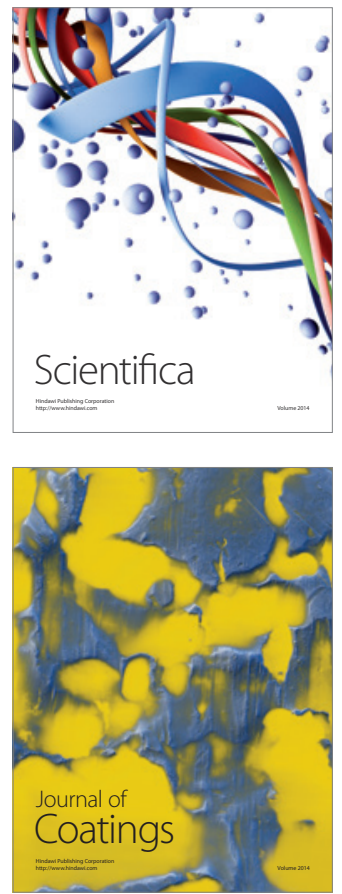
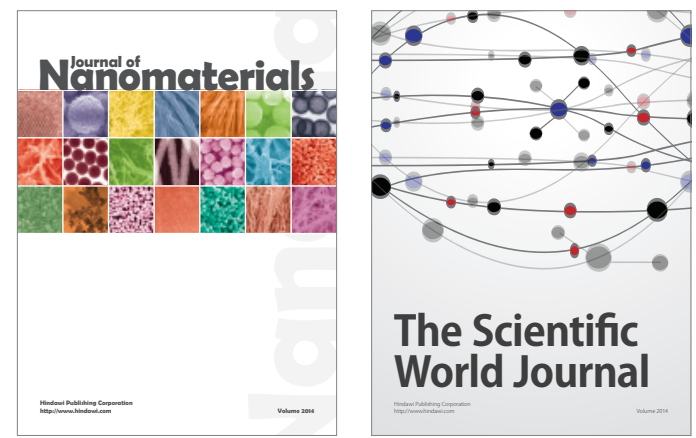

The Scientific World Journal
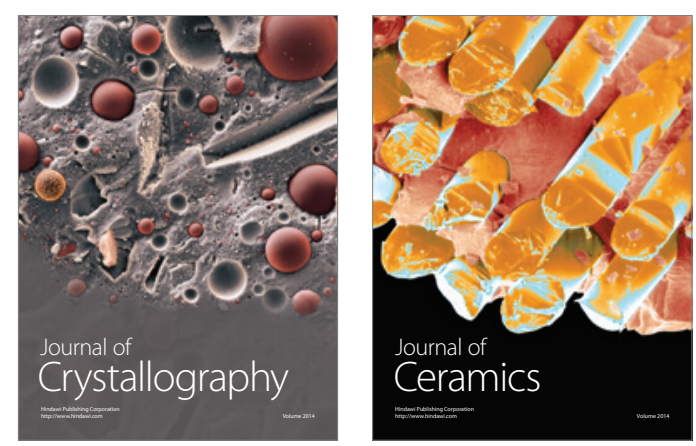
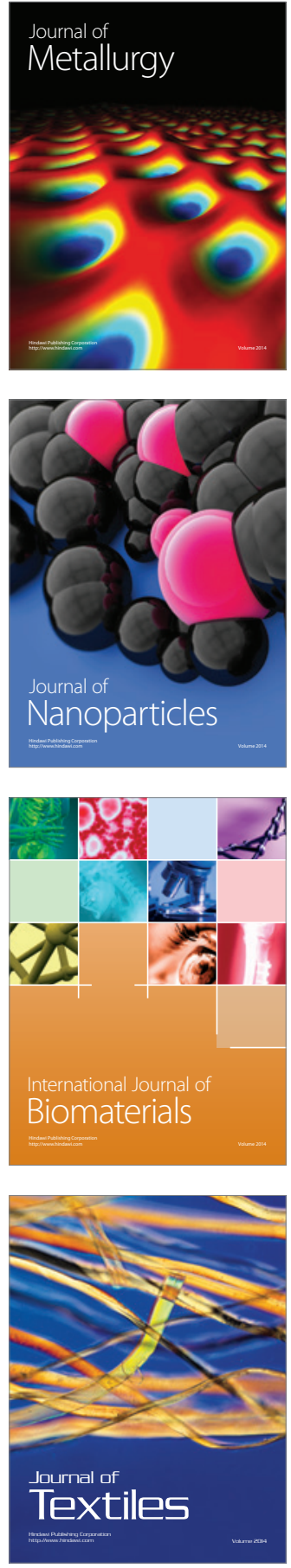